\title{
BMJ Open Cross-sectional association between long working hours and liver function: the Kangbuk Samsung Health Study
}

\author{
Eunchan Mun (D) , ${ }^{1}$ Woncheol Lee, ${ }^{1}$ Min-Woo Nam, ${ }^{1}$ Hyun-II Kim, ${ }^{1}$ \\ Hyeongcheol Kim, ${ }^{1}$ Yesung Lee, ${ }^{1}$ Soyoung Park ${ }^{1,2}$
}

To cite: Mun E, Lee W, Nam M-W, et al. Crosssectional association between long working hours and liver function: the Kangbuk Samsung Health Study. BMJ Open 2020;10:e041595. doi:10.1136/ bmjopen-2020-041595

- Prepublication history for this paper is available online. To view these files, please visit the journal online (http://dx.doi. org/10.1136/bmjopen-2020041595).

Received 12 June 2020 Revised 17 November 2020 Accepted 25 November 2020

A) Check for updates

(C) Author(s) (or their employer(s)) 2020. Re-use permitted under CC BY-NC. No commercial re-use. See rights and permissions. Published by BMJ.

${ }^{1}$ Department of Occupational and Environmental Medicine, Kangbuk Samsung Hospital, Sungkyunkwan University School of Medicine, Seoul, Republic of Korea

${ }^{2}$ Total Healthcare Center, Kangbuk Samsung Hospital, Sungkyunkwan University School of Medicine, Seoul, Republic of Korea

Correspondence to Dr Soyoung Park; syoem.park@gmail.com

\section{ABSTRACT}

Objectives Although the effects of long working hours on liver function remain unclear, in South Korea, there is a social perception that long working hours are associated with poor liver function. Thus, long working hours have recently become a major issue. This study aimed to determine the association between long working hours and liver function, as indicated by the alanine transaminase (ALT) levels.

Design Cross-sectional study.

Setting Large university hospitals in Seoul and Suwon, South Korea.

Participants Workers in formal employment who underwent a comprehensive health examination at the Kangbuk Samsung Hospital Total Healthcare Centre clinics in Seoul and Suwon, South Korea, between January 2011 and December 2018. Of the 386488 participants, 212421 met the inclusion criteria and were included in the analysis.

Primary outcome measure ALT elevation.

Results The participants were predominantly welleducated $(86.1 \%)$, male $(69.3 \%)$ and in their 30 s $(49.6 \%)$. In total, $13.4 \%$ of the participants presented ALT elevation (>40 IU/L). There was no significant association between working hours and ALT elevation in the general population and in the hepatitis B surface antigen ( $\mathrm{HBsAg}$ )-negative group. Conversely, in the $\mathrm{HBsAg}$-positive group, working $>60$ hours per week compared with 35-40 hours per week was significantly associated with ALT elevation. The association was more pronounced in those with ALT levels $>80 \mathrm{IU} / \mathrm{L}$ (OR 1.94, 95\% Cl 1.24 to 3.01 ) than in those with ALT levels $>40 \mathrm{IU} / \mathrm{L}$ (OR: $1.45,95 \% \mathrm{Cl} 1.20$ to 1.75). The $p$ values for trend were $<0.05$.

Conclusions Long working hours were associated with ALT elevation only in hepatitis B virus carriers and not in the general population. Provided that there is adherence to the legal working hours, there is no need to further restrict working hours for liver health, irrespective of $\mathrm{HBsAg}$ status.

\section{BACKGROUND}

Long working hours have recently become a major issue in South Korea. In 2018, the average working time of Korean workers was the third longest among the member countries of the Organisation for Economic Cooperation and Development. ${ }^{1}$ Previous studies

\section{Strengths and limitations of this study}

This study investigated a large sample size of 212421 participants for cross-sectional analyses.

- We adjusted the analyses for personal behavioural, social and occupational factors drawn from clinical records.

- We stratified the study group and analysed the modification of effect by the hepatitis B surface antigen-positive status, which is relatively difficult to measure.

- The generalisability of the study findings should be verified, as the study included well-educated Korean men and women in formal employment.

- The cross-sectional nature of the study design makes it difficult to determine causal inference.

have shown that long working hours could be associated with various clinical diseases, such as coronary heart disease, depression, ${ }^{2}$ diabetes mellitus, ${ }^{3}{ }^{4}$ non-alcoholic fatty liver disease, ${ }^{5}$ atrial fibrillation, ${ }^{6}$ hypertension ${ }^{78}$ and stroke. ${ }^{9}$

Although the effects of long working hours on liver function remain unclear, in South Korea, there is a social perception that long working hours are associated with poor liver function. Interestingly, in South Korea, there have been growing concerns regarding the potential for impaired liver function due to long working hours. The Ministry of Employment and Labour has failed to recognise most of these claims. However, the Supreme Court has ruled that long working hours were the main cause of death in a worker who died after exacerbation of hepatitis B virus (HBV) infection in July 2001. Since then, there has been a general perception among employers that $\mathrm{HBV}$ carriers are more vulnerable to the effects of long working hours than other workers, resulting in discrimination in hiring against $\mathrm{HBV}$ carriers. ${ }^{10}$

Moreover, some studies have shown that long working hours are associated with 
work-related psychosocial stress, ${ }^{11}{ }^{12}$ which may lead to adverse effects on liver function through immunemediated inflammation. ${ }^{13-17}$ Thus, long working hours can be considered to adversely affect liver function by increasing exposure to work-related psychosocial stress.

However, few studies to date have investigated the effects of long working hours on liver function. Therefore, this study aimed to determine the association between long working hours and liver function, as indicated by the alanine transaminase (ALT) levels, in the hepatitis B surface antigen ( $\mathrm{HBsAg}$ )-positive and HBsAgnegative groups.

\section{METHODS}

\section{Ethical considerations}

The requirement for informed consent was waived owing to the use of deidentified data.

\section{Study design and participants}

We conducted a cross-sectional study including participants of the Kangbuk Samsung Health Study who underwent a comprehensive health examination at the Kangbuk Samsung Hospital Total Healthcare Centre clinics in Seoul and Suwon, South Korea, between January 2011 and December 2018 ( $n=386488)$. The exclusion criteria were as follows: working $<35$ hours per week; missing data on working hours; history of cancer; administration of hepatotonics or antivirals against viral hepatitis; aspartate transaminase (AST)/ALT ratio $>2$, which is one of the specific findings of advanced alcoholic liver disease associated with excessive alcohol consumption ${ }^{18}$; and missing data on any covariates. In total, 212421 full-time workers were included in the analysis (figure 1).

\section{Measurement of variables}

Data on age, sex, smoking status, alcohol consumption, exercise habits, medication, marital status, education level and occupational information were obtained using

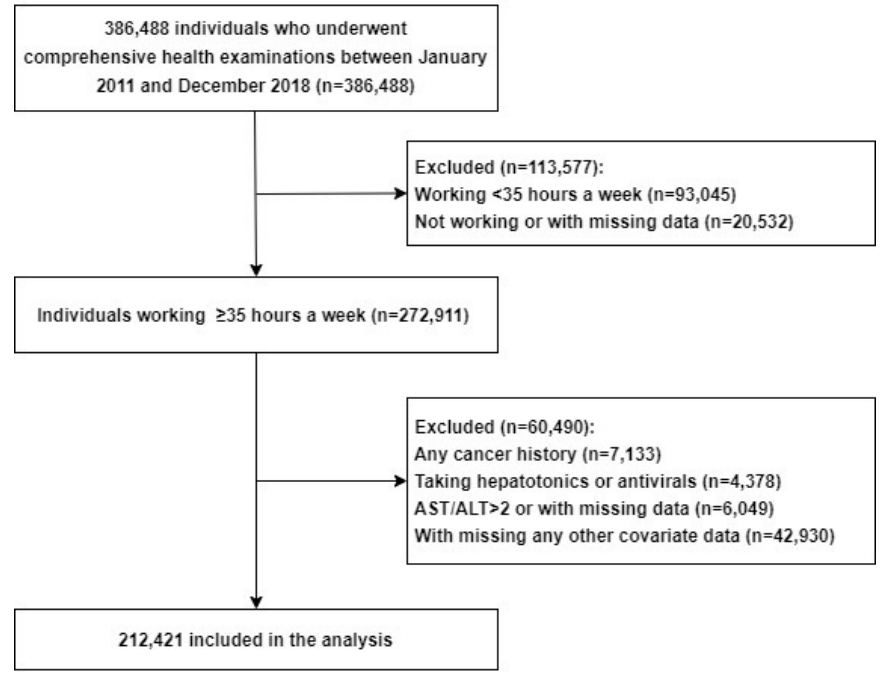

Figure 1 Participant selection flow chart. ALT, alanine transaminase; AST, aspartate transaminase. a self-administered questionnaire. Clinical factors, such as height, body weight and waist circumference, were measured by trained nurses, and blood parameters were measured using venous blood samples collected from the antecubital vein after $\geq 10$ hours of fasting.

The HBsAg status and serum insulin levels were determined using electrochemiluminescent immunoassays (Modular E170; Roche Diagnostics) between 2011 and 2015 and the Cobas Integra 8000 (Roche Diagnostics) analyser thereafter. The serum total cholesterol, highdensity lipoprotein cholesterol (HDL-C), low-density lipoprotein cholesterol (LDL-C) and triglyceride levels were measured via an enzymatic colorimetric assay. The serum fasting glucose levels were measured using the hexokinase method on the Cobas Integra 800 system (Roche Diagnostics). Similarly, the haemoglobin A1c (HbA1c) levels were measured using an immunoturbidimetric assay with the Cobas Integra 800 automatic analyser (Roche Diagnostics). Insulin resistance was assessed using the homeostasis model assessment for insulin resistance (HOMA-IR) according to the following equation: fasting blood insulin $(\mu \mathrm{U} / \mathrm{mL}) \times$ fasting serum glucose $(\mathrm{mmol} / \mathrm{L}) / 22.5{ }^{19}$

Moreover, the ALT levels were also measured using the Cobas Integra 800 (Roche Diagnostics) analyser. ALT elevation was defined as $>40$ or $>80 \mathrm{IU} / \mathrm{L}$ (two times the upper normal limit).

All laboratory tests were conducted at The Laboratory Medicine Department of Kangbuk Samsung Hospital in Seoul, South Korea, which has been accredited by the Korean Society of Laboratory Medicine and the Korean Association of Quality Assurance for Clinical Laboratories. The laboratory participates in the College of American Pathologists Survey Proficiency Testing.

\section{Definition of working hours}

Working hours were categorised based on the Korean Labour Standards Act, which defines 40 hours as the legal number of working hours per week and 52 hours as the maximum limit, including overtime. ${ }^{20}$ The categorisation was also based on the Korean Enforcement Decree of the Industrial Accident Compensation Insurance Act and Public Notice of Korean Ministry of Employment and Labour, which considers cerebrovascular and cardiovascular diseases caused by chronically long working hours as occupational diseases when the average number of working hours per week within the 12 week period immediately preceding a disease event is $>60$ hours. ${ }^{21} 22$ Accordingly, working hours in this study were classified into 35-40, 41-52, 53-60 and >60 hours per week, with long working hours defined as $>60$ hours per week.

\section{Primary outcome measure of liver function}

We adopted ALT levels as an indicator of liver function because they are commonly used and are clearly associated with the status and prognosis of liver disease. We set the following two cut-off values for ALT elevation: $>40$ and $>80 \mathrm{IU} / \mathrm{L}$, corresponding to mild and moderate elevation, respectively. 


\section{Statistical analyses}

A Kolmogorov-Smirnov normality test was performed. Non-normally distributed continuous variables were expressed as medians and IQRs and analysed using the Mann-Whitney U test. Categorical variables were expressed as numbers and percentages $(\%)$ and analysed using the $\chi^{2}$ test. Binary logistic regression was used to determine the association between working hours and ALT elevation ( $>40$ or $>80 \mathrm{IU} / \mathrm{L}$ ) by the HBsAg status, and the results were expressed as ORs with 95\% CIs. We performed bivariate logistic regression analysis, followed by age and sex adjustment and further multivariate adjustment for factors, such as smoking status, alcohol intake, body mass index (BMI), waist circumference, HDL-C, LDL-C, triglyceride levels, marital status, education level and night shift work. We additionally assessed the combined effects of exposure to long working hours and HBsAg-positive status with respect to ALT elevation ( $>40$ or $>80$ IU $/ \mathrm{L}$ ) by calculating the relative excess risk due to interaction (RERI) and the ratio of ORs. RERIs were calculated using the following formula:

$\mathrm{RERI}=\mathrm{OR}_{\text {(combined exposure to long working hours and HBsAg-positive status) }}-\mathrm{OR}$ (exposure to long working hours only) $-\mathrm{OR}$ (exposure to HBssg-positive status only) $+1 .{ }^{23}$

A RERI value $>0$ indicated a positive interaction on the additive scale. The ratios of ORs were calculated using the following formula:

$\mathrm{OR}$ ratio $=\mathrm{OR}$

status) $/\left(\mathrm{OR}_{\text {[exposure to long working hours only] }} \times \mathrm{OR}_{\text {[exposure to HBsAg-positive }}\right.$ status onlv] $)$.

An OR ratio $>1$ indicated a positive interaction on the multiplicative scale. All statistical analyses were performed using SPSS software (V.24.0). A p value $<0.05$ was considered statistically significant.

\section{Patient and public involvement}

Patients and/or the public were not involved in the design, conduct, reporting or dissemination plans of this research.

\section{RESULTS}

\section{Participant characteristics}

The median age was 36 (IQR 31-42) years, and the majority $(69.3 \%)$ of participants were men. Most of them were married $(73.7 \%)$, well educated $(86.1 \%)$ and white-collar workers $(90.0 \%)$. In total, $13.4 \%$ of participants had elevated ALT levels (>40 IU/L). There were significant differences in age, sex, smoking status, alcohol intake, marital status, education level, night shift work, HOMA-IR, BMI, waist circumference, HBsAg status, medication and working hours, and in total cholesterol, HDL-C, LDL-C, triglyceride, glucose and $\mathrm{HbA} 1 \mathrm{c}$ levels between the elevated and normal ALT groups (table 1).

\section{Association between working hours and ALT elevation by the HBsAg status}

In the fully adjusted logistic regression model, there was no significant association between the working hours and
ALT elevation ( $>40$ or $>80$ IU $/ \mathrm{L}$ ) in the general population and in the HBsAg-negative group. Conversely, in the HBsAg-positive group, working $>60$ hours compared with 35-40 hours per week was significantly associated with ALT elevation. The association was more pronounced in those with ALT levels $>80$ IU/L (OR: 1.94, 95\% CI 1.24 to 3.01) than in those with ALT levels $>40 \mathrm{IU} / \mathrm{L}$ (OR: 1.45, $95 \%$ CI 1.20 to 1.75 ). Interestingly, the p values for trend were both $<0.05$ (table 2 ).

\section{Modification of the effect of long working hours on ALT elevation by the $\mathrm{HBsAg}$-positive status}

The HBsAg-positive status showed a positive effect modification on ALT elevation from exposure to working $>60$ hours per week. For ALT levels $>40$ IU $/$ L, the RERI was 0.67 and the ratio of ORs was 1.28. For ALT levels $>80 \mathrm{IU} / \mathrm{L}$, the RERI was 1.65 , and the ratio of ORs was 1.65. Thus, the effect modification was positive on the additive and multiplicative scales, and the positive effect modification was more pronounced when the ALT levels were $>80 \mathrm{IU} / \mathrm{L}$ than $>40 \mathrm{IU} / \mathrm{L}$ (table 3 ).

\section{DISCUSSION}

\section{Principal findings}

Although long working hours are considered to have adverse effects on liver function, there are limited studies that focused on this association. In this study, we found that long working hours were adversely associated with liver function, as indicated by the elevated ALT levels, but only in the HBsAg-positive group. Additionally, the effect of long working hours on ALT elevation was positively modified by the HBsAg status. The association and effect modification were more pronounced when the ALT levels were $>80 \mathrm{IU} / \mathrm{L}$ than $>40 \mathrm{IU} / \mathrm{L}$.

\section{ALT level as a biomarker for liver function}

Liver function can be reflected by several biomarkers such as ALT, AST, gamma-glutamyltransferase, platelet and albumin levels. Although the ALT level alone should not be used to determine liver function strictly, it is the most commonly used indicator and is clearly associated with liver disease status and prognosis. Kim et $a l^{24}$ showed a strong positive correlation between the ALT level and the risk of liver-related mortality. It is also known that recurrent ALT flares increase the risk of developing cirrhosis and hepatocellular carcinoma through cellular immune response in $\mathrm{HBV}$ carriers. $^{25}$

\section{Psychosocial stress and liver-related health}

Psychosocial stress can increase the ALT levels through immune-mediated inflammation by activation of the hypothalamic-pituitary-adrenal axis and the autonomic nervous system. Thus, secreted glucocorticoids and cytokines play an important role in ALT elevation. ${ }^{13-17}$ Long working hours can be partly involved in this mechanism by increasing the exposure to work-related psychosocial stress. ${ }^{11} 12$ Accordingly, our results may partly reflect the 
Table 1 General characteristics of the study participants

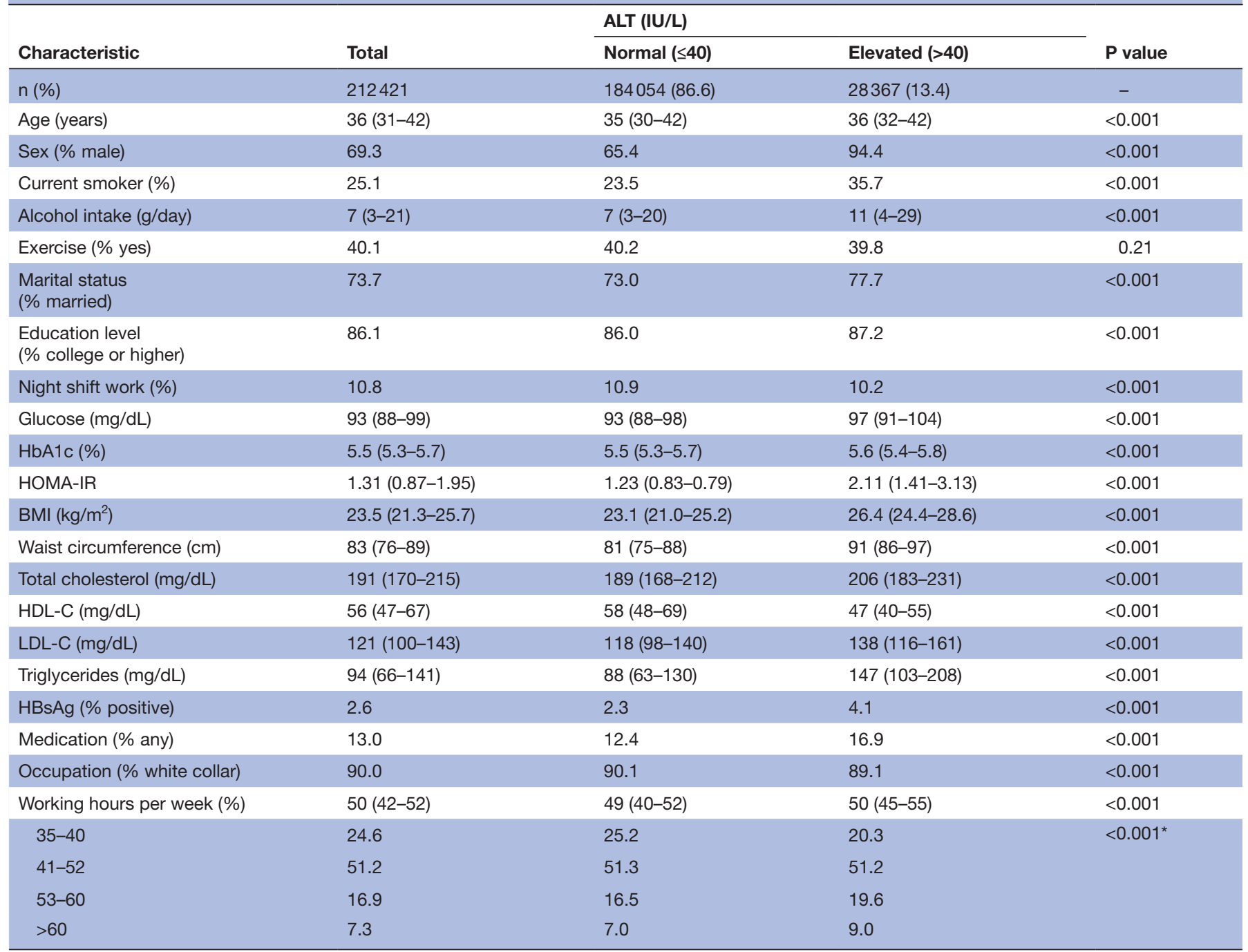

Data are presented as medians (IQR) or numbers (percentage).

$* 4 \times 2 \chi^{2}$ test.

ALT, alanine transaminase; BMI, body mass index; HbA1c, haemoglobin A1c; HBsAg, hepatitis B surface antigen; HDL-C, high-density lipoprotein cholesterol; HOMA-IR, homeostasis model assessment of insulin resistance; LDL-C, low-density lipoprotein cholesterol.

effects of psychosocial stress caused by long working hours. This assumption should be confirmed by further investigation in future studies.

\section{Relevant personal health behaviour factors and other potent confounders}

We have adjusted for several confounders in logistic regression analysis to focus on the effects of long working hours. Working for many hours may lead to changes in health behaviours, such as increased alcohol consumption and smoking, although this relationship remains controversial. ${ }^{26} 27$ Therefore, smoking status and alcohol intake were considered as potent confounders; thus, they were included in the multivariate-adjusted regression model. Independently of the personal health behaviours, low socioeconomic status was known to be associated with liver diseases through the cascade starting with psychiatric disorders through to substance abuse and self-harm. ${ }^{28}$ Night shift work was also positively associated with abnormal liver function owing to circadian disruption. ${ }^{29}$ Lipid metabolites were found to be closely related to obesity and, as they are metabolised in liver, they are associated with liver function. ${ }^{30}$ Therefore, to focus on the effect of working for many hours, we adjusted for all potent confounders, such as personal behavioural, social, occupational and clinical factors.

\section{Effects of work-related psychosocial stress in the HBsAg- positive group}

Psychosocial stress also influences the clinical course of viral hepatitis. Several studies have shown that psychosocial stress adversely affects the immune system and severity of viral hepatitis. ${ }^{31-34}$ Thus, it is reasonable to expect that long working hours can cause work-related psychosocial stress and ALT elevation in the HBsAgpositive group. Furthermore, we found a positive effect modification of the HBsAg-positive status. However, the 
Table 2 Association between working hours and ALT elevation by HBsAg status

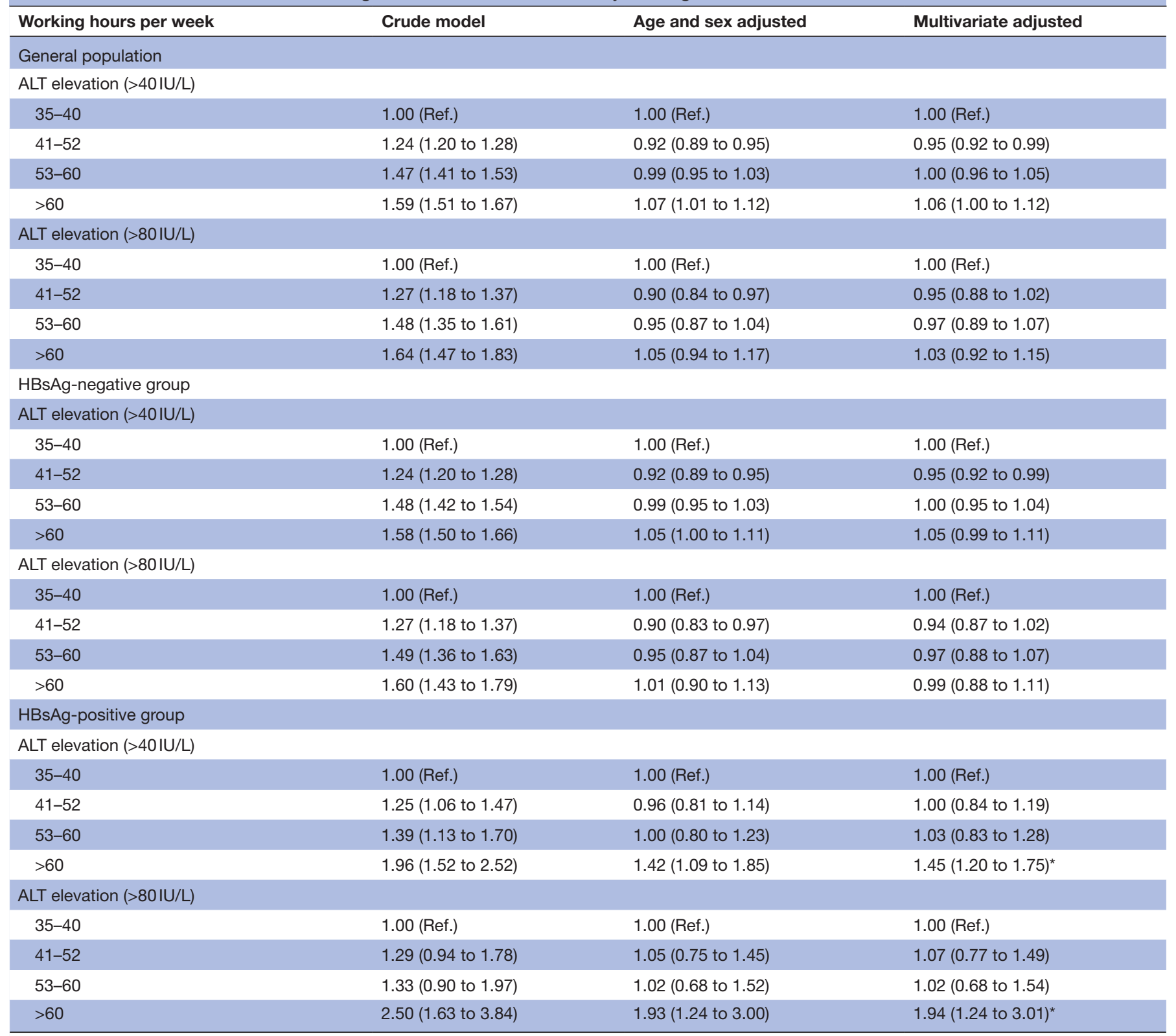

The multivariate model was adjusted for age, sex, smoking status, alcohol intake, marital status, education level, night shift work, BMI, waist circumference, HDL-C levels, LDL-C levels and triglyceride levels.

${ }^{*} \mathrm{P}$ for trend $<0.05$.

ALT, alanine transaminase; BMI, body mass index; HBsAg, hepatitis B surface antigen; HDL-C, high-density lipoprotein cholesterol; LDL-C, low-density lipoprotein cholesterol; Ref., reference.

same results were not obtained in the general population. This is probably because working for many hours may only have a significant effect on individuals who experience a positive effect modification of the HBsAgpositive status.

\section{Previous studies evaluating long working hours and liver function}

There are limited studies that focused on the association between long working hours and liver function. Ochiai $e t$ $a l^{35}$ showed that working hours were not associated with elevated ALT levels among Japanese employees. However, they did not consider the influence of important factors such as alcohol intake, smoking status and medication. In contrast, we included these factors in our analysis to reduce confounding bias. Virtanen $e t a l^{36}$ showed that long working hours were associated with elevated ALT levels in men. They specifically attributed these findings to adverse metabolic changes, as BMI is a mediator of the association between long working hours and ALT. However, we found consistent results, even after further adjustment for BMI and other metabolic factors, such as waist circumference, HDL-C, LDL-C and triglyceride levels (table 2). Indeed, the association between long working hours and metabolic changes remains controversial..$^{37}$ 
Table 3 Modification of the effect of long working hours ( $>60$ hours per week) on ALT elevation by the HBsAg-positive status

OR $(95 \% \mathrm{Cl})$ for ALT elevation within strata of HBsAg-positive

HBsAg-positive status Working 35-60 hours per week Working $>60$ hours per week status

\begin{tabular}{|c|c|c|c|}
\hline \multicolumn{4}{|c|}{ ALT elevation (>40IU/L) } \\
\hline Negative & 1.00 (Ref.) & 1.08 (1.02 to 1.13$)$ & 1.08 (1.02 to 1.13$)$ \\
\hline Positive & 1.97 (1.82 to 2.13$)$ & 2.72 (2.14 to 3.45$)$ & $1.43(1.13$ to 1.81$)$ \\
\hline Negative & 1.00 (Ref.) & 1.03 (0.93 to 1.14$)$ & 1.03 (0.93 to 1.14$)$ \\
\hline Positive & 2.39 (2.08 to 2.75$)$ & 4.07 (2.83 to 5.86$)$ & 1.85 (1.29 to 2.67$)$ \\
\hline
\end{tabular}

Measure of interaction on additive scale with respect to ALT elevation ( $>40$ and $>80$ IU/L): RERI, 0.67 and 1.65, respectively.

Measure of interaction on multiplicative scale with respect to ALT elevation ( $>40$ and $>80 \mathrm{IU} / \mathrm{L})$ : ratio of ORs, 1.28 and 1.65 , respectively. ORs and 95\% Cls were adjusted for age, sex, smoking status, alcohol intake, marital status, education level, night shift work, BMI, waist circumference, HDL-C levels, LDL-C levels and triglyceride levels.

ALT, alanine transaminase; BMI, body mass index; HBsAg, hepatitis B surface antigen; HDL-C, high-density lipoprotein cholesterol; LDL-C, lowdensity lipoprotein cholesterol; OR, odds ratio; Ref., reference; RERI, relative excess risk due to interaction.

\section{Strengths and limitations}

Our study had several limitations. First, its crosssectional design makes it difficult to determine causality. Cohort or longitudinal studies are required to confirm the causal nature of the relationship. Second, even at the same working time, the effect of working hours on liver function might be different because occupational factors, such as the type of work, intensity of the work and exposure to hazardous substances, were not adequately considered. Further research is needed to consider specific and concrete occupational factors and analyse the effects of working for many hours. Third, data on working hours were collected from a self-reported questionnaire, which may have resulted in information bias. Fourth, only night shift work was investigated, and sleeping hours were not included in the analysis. Several studies have shown that night shift work and sleeping hours affect liver function. ${ }^{29} 3839$ Therefore, both should be included in the multivariate model in future studies. Finally, our study included relatively well-educated Korean men and women who were mostly white-collar workers in formal employment. Therefore, our results may not be representative of the general working population. This may have limited our analysis findings regarding the effects of occupation and socioeconomic status on liver function. The effects of long working hours may be greater in the poorer work force and, therefore, may have been underestimated in our study. The generalisability of our findings to other populations still needs to be verified. Despite these limitations, we believe that our study remains valuable because, to the best of our knowledge, it was the first large-scale study conducted in South Korea that evaluated the association between long working hours and liver function using interaction analysis.

\section{Implications}

Our findings should not be misinterpreted, as they indicated that the working hours of HBV carriers must be limited. Although liver function deteriorated when the working hours exceeded 60 hours per week in the HBsAg-positive group, there was no effect on liver function within legal working hours. Many studies have addressed other adverse health effects; however, there was no obvious association between long working hours and liver function in the general population.

\section{CONCLUSIONS}

Long working hours were not associated with liver function in the general population. However, working $>60$ hours per week was associated with elevated ALT levels in HBV carriers. A positive effect modification of long working hours on liver function by HBsAg-positive status was also observed. Provided that there is adherence to the legal working hours, there is no need to further restrict working hours for liver health, irrespective of HBsAg status. Furthermore, HBV carriers must not be discriminated against in the workplace because there is no obvious association between legal working hours and liver function, even in HBV carriers.

Contributors EM, WL and SP contributed to the conception and design of the study. EM, M-WN, H-IK, HK, YL and SP participated in the data collection and have made substantial contributions to the statistical analysis and interpretation of the data. EM and SP prepared the first draft of the manuscript. WL and SP have made substantial contributions to revising the manuscript critically for important intellectual content. All authors have approved the final version submitted for publication.

Funding The authors have not declared a specific grant for this research from any funding agency in the public, commercial or not-for-profit sectors.

Competing interests None declared.

Patient consent for publication Not required.

Ethics approval The study was approved by the Institutional Review Board of Kangbuk Samsung Hospital (approval number: KBSMC 2020-02-049).

Provenance and peer review Not commissioned; externally peer reviewed.

Data availability statement Data are available on reasonable request. The datasets used and/or analysed during the current study are available from the corresponding author on reasonable request.

Open access This is an open access article distributed in accordance with the Creative Commons Attribution Non Commercial (CC BY-NC 4.0) license, which 
permits others to distribute, remix, adapt, build upon this work non-commercially, and license their derivative works on different terms, provided the original work is properly cited, appropriate credit is given, any changes made indicated, and the use is non-commercial. See: http://creativecommons.org/licenses/by-nc/4.0/.

\section{ORCID iD}

Eunchan Mun http://orcid.org/0000-0002-2808-0423

\section{REFERENCES}

1 OECD. Hours worked (indicator), 2019. Available: www.oecd-ilibrary. org/employment/hours-worked/indicator/english_47be1c78-en [Accessed 5 Feb 2020].

2 Bannai A, Tamakoshi A. The association between long working hours and health: a systematic review of epidemiological evidence. Scand $J$ Work Environ Health 2014;40:5-18.

3 Bannai A, Yoshioka E, Saijo Y, et al. The risk of developing diabetes in association with long working hours differs by shift work schedules. J Epidemiol 2016;26:481-7.

4 Baek Y, Kim M, Kim GR, et al. Cross-Sectional study of the association between long working hours and pre-diabetes: 20102017 Korea National health and nutrition examination survey. BMJ Open 2019;9:e033579.

5 Park H, Lee S-J. Working hours and nonalcoholic fatty liver disease according to sleep duration. Chronobiol Int 2019;36:1671-80.

6 Kivimäki M, Nyberg ST, Batty GD, et al. Long working hours as a risk factor for atrial fibrillation: a multi-cohort study. Eur Heart $J$ 2017;38:2621-8.

7 Trudel X, Brisson C, Gilbert-Ouimet M, et al. Long working hours and the prevalence of masked and sustained hypertension. Hypertension 2020;75:532-8.

8 Yoo DH, Kang M-yeol, Paek D, et al. Effect of long working hours on self-reported hypertension among middle-aged and older wage workers. Ann of Occup and Environ Med 2014;26:25.

9 Fadel M, Sembajwe G, Gagliardi D, et al. Association between reported long working hours and history of stroke in the CONSTANCES cohort. Stroke 2019;50:1879-82.

10 Ministry of Employment and Labor (KR). Study of the workrelatedness between hazard factors such as overwork, stress, work type and working hours and occupational cancer. Sejong: Ministry of Employment and Labor, 2019. www.prism.go.kr/homepage/ researchCommon/downloadResearchAttachFile.do?work key $=001 \&$ file_type $=C P R \& s e q \_n o=001 \& p d f \_c o n v \_y n=Y \& r e s e a r c h \_i d=1490000-$ 201900041

11 Wong K, Chan AHS, Ngan SC. The effect of long working hours and overtime on occupational health: a meta-analysis of evidence from 1998 to 2018. Int J Environ Res Public Health 2019;16:2102.

12 Lee K, Suh C, Kim JE, et al. The impact of long working hours on psychosocial stress response among white-collar workers. Ind Health 2017;55:46-53.

13 Zhang S, Ma C, Wang X. Impact of chronic psychological stress on nonalcoholic fatty liver disease. Int J Clin Exp Med 2019;12:7991-8.

14 Chida Y, Sudo N, Kubo C. Does stress exacerbate liver diseases? J Gastroenterol Hepatol 2006;21:202-8.

15 Joung Jin-Yong, Cho Jung-Hyo, Kim Yun-Hee, et al. A literature review for the mechanisms of stress-induced liver injury. Brain Behav 2019;9:e01235.

16 Dunn C, Brunetto M, Reynolds G, et al. Cytokines induced during chronic hepatitis B virus infection promote a pathway for NK cellmediated liver damage. J Exp Med 2007;204:667-80.

17 Vere CC, Streba CT, Streba LM, et al. Psychosocial stress and liver disease status. WJG 2009;15:2980-6.

18 Sorbi D, Boynton J, Lindor KD. The ratio of aspartate aminotransferase to alanine aminotransferase: potential value in differentiating nonalcoholic steatohepatitis from alcoholic liver disease. Am J Gastroenterol 1999;94:1018-22.

19 Matthews DR, Hosker JP, Rudenski AS, et al. Homeostasis model assessment: insulin resistance and ?-cell function from fasting plasma glucose and insulin concentrations in man. Diabetologia 1985;28:412-9.

20 Ministry of Employment and Labor (KR). Chapter IV: working hours and recess. in: labor standard act. Sejong: Ministry of Employment and Labor, 2012. www.moel.go.kr/english/download_eng.jsp?type=\& file=(31)LABORSTANDARDSACT_2012.pdf

21 Ministry of Employment and Labor (KR). Korean enforcement decree of the industrial accident compensation insurance act and public notice of what is necessary to determine approval for cerebrocardiovascular disease and musculoskeletal disease as occupational diseases. Sejong: Ministry of Employment and Labor, 2017. www. law.go.kr/LSW//admRullnfoP.do?admRulSeq=2100000107994

22 Park J, Kim Y, Han B. Long working hours in Korea: based on the 2014 Korean working conditions survey. Saf Health Work 2017;8:343-6.

$23 \mathrm{Knol}$ MJ, VanderWeele TJ. Recommendations for presenting analyses of effect modification and interaction. Int J Epidemiol 2012:41:514-20.

$24 \mathrm{Kim} \mathrm{HC}$, Nam CM, Jee SH, et al. Normal serum aminotransferase concentration and risk of mortality from liver diseases: prospective cohort study. BMJ 2004;328:983.

25 Liaw Y-F, Chu C-M. Hepatitis B virus infection. The Lancet 2009;373:582-92.

26 Albertsen K, Borg V, Oldenburg B. A systematic review of the impact of work environment on smoking cessation, relapse and amount smoked. Prev Med 2006;43:291-305.

27 Virtanen M, Jokela M, Nyberg ST, et al. Long working hours and alcohol use: systematic review and meta-analysis of published studies and unpublished individual participant data. BMJ 2015;350:g7772.

28 Kivimäki M, Batty GD, Pentti J, et al. Association between socioeconomic status and the development of mental and physical health conditions in adulthood: a multi-cohort study. Lancet Public Health 2020;5:e140-9.

29 Wang F, Zhang L, Wu S, et al. Night shift work and abnormal liver function: is non-alcohol fatty liver a necessary mediator? Occup Environ Med 2019;76:83-9.

30 Gluchowski NL, Becuwe M, Walther TC, et al. Lipid droplets and liver disease: from basic biology to clinical implications. Nat Rev Gastroenterol Hepatol 2017; 14:343-55.

31 Nagano J, Nagase S, Sudo N, et al. Psychosocial stress, personality, and the severity of chronic hepatitis C. Psychosomatics 2004;45:100-6.

32 Kunkel EJS, Sung Kim J, Hann H-W, et al. Depression in Korean immigrants with hepatitis $B$ and related liver diseases. Psychosomatics 2000;41:472-80.

33 Burns VE, Carroll D, Ring C, et al. Stress, coping, and hepatitis B antibody status. Psychosom Med 2002;64:287-93.

34 Kakimi K, Guidotti LG, Koezuka Y, et al. Natural killer T cell activation inhibits hepatitis B virus replication in vivo. J Exp Med 2000;192:921-30.

35 Ochiai Y, Takahashi M, Matsuo T, et al. Objective and subjective working hours and their roles on workers' health among Japanese employees. Ind Health 2020;58:265-75

36 Virtanen M, Magnusson Hansson L, Goldberg M, et al. Long working hours, anthropometry, lung function, blood pressure and bloodbased biomarkers: cross-sectional findings from the CONSTANCES study. J Epidemiol Community Health 2019;73:130-5.

37 Pimenta AM, Bes-Rastrollo M, Sayon-Orea C, et al. Working hours and incidence of metabolic syndrome and its components in a Mediterranean cohort: the sun project. Eur $J$ Public Health 2015;25:683-8.

38 Wijarnpreecha K, Thongprayoon C, Panjawatanan P, et al. Short sleep duration and risk of nonalcoholic fatty liver disease: a systematic review and meta-analysis. J Gastroenterol Hepatol 2016;31:1802-7.

39 Okamura T, Hashimoto Y, Hamaguchi M, et al. Short sleep duration is a risk of incident nonalcoholic fatty liver disease: a population-based longitudinal study. JGLD 2019;28:73-81. 